\title{
Reflecting on tuberculosis case notification and treatment outcomes in the Volta region of Ghana: a retrospective pool analysis of a multicentre cohort from 2013 to 2017
}

Eric Osei ${ }^{i^{*}}$ (D), Samuel Oppong², Daniel Adanfo², Bless Ativor Doepe ${ }^{2}$, Andrews Owusu², Augustine Goma Kupour ${ }^{2}$ and Joyce Der ${ }^{2}$

\begin{abstract}
Background: Tuberculosis (TB) remains a petrified condition with a huge economic and health impact on families and health systems in Ghana. Monitoring of TB programme performance indicators can provide reliable data for direct measurement of TB incidence and mortality. This study reflects on the trends of TB case notification and treatment outcomes and makes comparison among 10 districts of the Volta region of Ghana.
\end{abstract}

Methods: This was a retrospective analysis of surveillance data of a cohort of TB cases from 2013 to 2017. Trends of case notification and treatment outcomes were examined and compared. Logistic regression was used to determine the independent relationship between patients and disease characteristics and unsuccessful treatment outcomes. Odds ratios, 95\% confidence intervals and $p$-values were estimated.

Results: A gradual declining trend of case notification of all forms of TB was noticed, with an overall case notification rate (CNR) of 65 cases per 100,000 population during the period. A wide variation of case notification of TB was observed among the districts, ranging from 32 to 124 cases per 100,000 population. Similarly, treatment success rate decreased slightly from $83.1 \%$ during the first year to $80.2 \%$ in 2017 , with an overall treatment success rate of $82.5 \%$ (95\% Cl: $81.3-83.8 \%$ ). Treatment failure, death, and lost to follow up rates were $0.8 \%$ (range $0.5-1.2 \%$ ), $13.5 \%$ (range 12.4-14.7\%), and 3.1\% (range 2.6-3.8\%) respectively. The treatment success rate among districts ranged from $70.5 \%$ in South Tongu to $90.8 \%$ in Krachi West district. Returned after treatment interruption (Adjusted odds ratio [AOR]: 3.62; 95\% Cl: 1.66-7.91; $P<0.001$ ) and TB/HIV co-infection (AOR: 1.94; 95\% Cl: 1.57-2.40; $P<0.001$ ) predicts poor treatment outcomes.

Conclusion: Over the past five years, TB case notification and successful treatment outcomes did not significantly improve. Wide district variations in CNR was observed. The overall treatment success rate observed in this study is below the target of $>90 \%$ set by the World Health Organization's (WHO) end TB strategy. Additionally, patients who returned to continue treatment after interruption and those who were co-infected with HIV strongly predict unsuccessful treatment outcomes. Sustained interventions to prevent treatment interruptions and improved management of co-morbidities can enhance treatment outcomes, as required to achieve the elimination goal.

Keywords: Tuberculosis, Case notification, Treatment outcomes, Volta region, Ghana

\footnotetext{
*Correspondence: eosei@uhas.edu.gh

'Department of Population and Behavioural Sciences, School of Public

Health, University of Health and Allied Sciences, Ho, Ghana

Full list of author information is available at the end of the article
}

(c) The Author(s). 2019 Open Access This article is distributed under the terms of the Creative Commons Attribution 4.0 International License (http://creativecommons.org/licenses/by/4.0/), which permits unrestricted use, distribution, and reproduction in any medium, provided you give appropriate credit to the original author(s) and the source, provide a link to the Creative Commons license, and indicate if changes were made. The Creative Commons Public Domain Dedication waiver (http://creativecommons.org/publicdomain/zero/1.0/) applies to the data made available in this article, unless otherwise stated. 


\section{Background}

Despite the availability of effective drug treatment since the 1940s, coupled with social and economic development, Tuberculosis (TB) remains a major public health problem globally, with millions of people affected by the disease each year. Geographically, the burden of TB is highest in Asia and the Africa regions, with Africa accounting for about $25 \%$ of global TB incident cases [1]. Globally, about 10 million people were estimated to have developed TB disease in 2017, however, only 6.4 million (64\%) were notified to national authorities and then to the World Health Organization (WHO). The shortfall in numbers could be due to underreporting of diagnosed cases or people not being diagnosed when they seek care, or they do not seek care at all [2]..

The major goals of Tuberculosis treatment are to cure the individual with the disease, reduce death and disability, and minimize the spread of Mycobacterium tuberculosis to other persons in the community. Nonadherence to TB treatment could lead to treatment failure, relapse, development of drug resistance, and prolonged infectiousness of patients [3]. Cognizant of this fact, the WHO introduced Directly Observed Treatment Shortcourse (DOTS) as a standard strategy for TB control since 1993. The aim of the strategy is for all National TB control programmes to detect at least $70 \%$ of estimated infectious cases and successfully treat $85 \%$ of them [4].

In Ghana, TB has remained a petrified condition for many years with a huge economic and health impact on individuals as well as the health system in general [5]. In 2018, 13,978 incident cases of TB, representing $32 \%$ of expected cases were detected in the country and notified to WHO [2] Recent national TB prevalence survey in 2013 estimated a prevalence of 264 cases per 100,000 population for all forms of TB and bacteriological prevalence of 356 per 100,000 population with smear-positive rate of 105 per 100,000 population [6], indicating that TB is still a major public health challenge in Ghana.

Standardized monitoring of notifications of TB cases and their treatment outcomes has been ongoing since 1995. In the era of the End TB Strategy and Sustainable Development Goals (SDGs), such monitoring needs to be sustained, together with unrelenting efforts to improve case notification in order to provide reliable data for direct measurement of TB incidence and mortality [2]. Additionally, such analysis enables National Tuberculosis Programmes to monitor trends in the occurrence and distribution of TB cases across a geographical location [1]. Few studies in Ghana, have reported TB treatment outcomes. However, none of these studies made a comparison of districts. Tetteh and colleagues, for instance, used data from a referral hospital [7], while Amo-Adjei et al. [5] used national data to make regional comparison. Furthermore, to the best of our literature search, no study has assessed the trends of TB case notification in Ghana. This study, therefore, reflects on the trends of TB case notification and treatment outcomes from 2013 to 2017 and made comparison among 10 districts in the Volta region of Ghana.

\section{Materials and methods}

\section{Study settings and design}

We conducted a retrospective cross-sectional study of all TB cases registered from 2013 to 2017 in 10 TB Basic Management Units (BMU)/ districts of the Volta Region of Ghana. A BMU is defined in terms of management, supervision, and monitoring responsibilities. Each unit had one or more treatment centres, laboratories, and a hospital. There is a coordinator who oversees TB control activities for the unit and maintains a master register of all Patients with TB being treated. The Volta Region is bound to the north by the Northern Region, the south by the Gulf of Guinea, west by the Volta Lake and the east by the Republic of Togo. It is divided into three natural geographical belts namely the southern, middle and the northern belts and has 25 administrative districts with 377 health facilities, serving a population of over 2, 789,211 . There are 44 DOTS centres and 41 laboratories in the region that provide $\mathrm{TB}$ diagnostic and treatment services to TB clients. At the DOTS centres, TB diagnosis, treatment, and monitoring are done as per the national tuberculosis control program (NTBCP) guidelines [8]. As in all other parts of Ghana, there are also TB/ HIV collaborative activities at all DOTS centres in the region.

\section{Sampling and study population}

For representativeness, stratified sampling was used to select participating districts. Strata were the geographical belts (southern, middle and northern) of the region. Five districts in the region did not have data from 2013, hence were not included in the strata for selection. Ten (50\%) districts were then selected from the remaining twenty. We randomly selected four districts each from the South (Keta, Ketu South, Central Tongu, and South Tongu) and Northern (Nkwanta South, Krachi West, Kadjebi, and Krachi East); and two from the middle belt (Kpando and Hohoe) using probability proportion to the number of districts in each stratum. Study population constituted patients with all forms of $\mathrm{TB}$ who were registered and commenced anti-TB treatment between 1st January 2013 and 31st December 2017 in the participating districts.

\section{Data source and extraction}

Data were extracted from the master registers of each BMU. The registers are provided by the Ghana NTBCP and are used by all districts in Ghana. The registers are 
used to record information of all Patients with TB been treated at all DOTS centres in the districts, which is used to monitor the programme and report on indicators to the higher level. Information contained in the register include patients' demographics; type and category of TB; initial and follow up sputum smear examination results; treatment outcomes; and TB/HIV collaborative activities. Data were extracted directly into Microsoft Excel spreadsheet designed to capture all relevant variables. Data extractions were done by the researchers in the presence of District health staffs. Variables such as age, sex, types of TB, co-morbidity with HIV/AIDS, and treatment outcomes were extracted for analysis. To ensure data quality and accuracy, the district TB focal persons were made to systematically check and compare extracted data with the source document. Data were cleaned to check for consistency and completeness of the data set before exporting for analysis.

\section{Outcome measures and definitions}

We assessed the outcome measures of TB treatment in this study as percentages of successful and unsuccessful outcomes among all patients who started treatment. Successful treatment outcomes included cured patients and those who completed treatment. Unsuccessful treatment outcomes included failures, lost to follow-ups and deaths. We excluded transferred out and those whose outcomes were missing in our analysis of treatment outcomes. We used WHO's definitions for surveillance of Patients with TB before and after treatment [9].

\section{Data handling and analysis}

Data was exported into Stata Version 13.1 (Stata Corp, College Station, Texas, USA) for analysis. Data were summarized using frequencies and proportions to describe the study population in relation to relevant variables. Case Notification Rate (CNR) was computed as the total number of cases notified divided by the estimated annual population and was expressed in 100,000. We used the Chi-square test to compare two proportions and applied trend tests across the 5 years to test for changes in CNR and treatment outcome trends. Bivariate and multivariate logistic regression were used to identify significant predictors of unsuccessful treatment outcomes, which was the main outcome variable, defined as patients who died, were lost to follow up or failed treatment. First, the association of unsuccessful treatment outcomes with each variable of interest was examined, ignoring all other variables. Second, variables with $p$-value $<0.05$ were considered for inclusion to construct a model with risk factors independently associated with unsuccessful treatment outcomes. Patients' age, sex, category and type of TB, TB/HIV co-morbidity, district, and year of treatment were included as covariates. The degree of association between dependent and independent variables was assessed using odds ratios (OR) with 95\% confidence intervals (CI). To test for the goodness of fit for the model, we used the likelihood ratio test to compare the likelihood of the data under the full model against the likelihood of the data under a model with reduced independent variables and since the $p$-value for the overall model fit statistic was less than 0.05 , we concluded that the model is good.

\section{Ethical statement}

Ethical approval was obtained from the University of Health and Allied Sciences ethical review committee. Informed consent was not obtained since there was no direct contact with patients. Patients' identifying information were not collected from the registers. Permission was sought from the Volta regional health Director and District Directors of participating districts before data were extracted. Data extractions were done in the presence of district health staff.

\section{Results \\ General characteristics of study subjects}

Over the 5 years, $3735 \mathrm{~TB}$ cases of all forms were reported in the study districts, of whom ages ranged between 1 and 96 years, with median (interquartile range) age of 44 (19-69) years. Children under 15 years accounted for $4.3 \%$ (161) of all reported cases, while $15.4 \%$ (574) were elderly (64+ years). Majority (2335; $62.5 \%)$ were males, most 3578 (95.8\%) were registered as new cases, while 138 (3.7\%) were retreatment cases, among which $55(1.5 \%)$ were relapse, $33(0.8 \%)$ were returned after default, and $25(0.7 \%)$ were treatment failure cases. Of all reported cases, 1712 (45.8\%) were pulmonary bacteriologically confirmed, 1900 (50.9\%) were smear-negative cases, while 116 (3.1\%) were extrapulmonary TB cases. Regarding HIV status, 712 (19.1\%) of all cases were HIV positive, while HIV status of 591 $(15.8 \%)$ was unknown. Majority $(1125 ; 30.1 \%)$ of cases were from Ketu South District, followed by Keta and Hohoe (11.8 and 11\%), and the least (123; 3.3\%) from Krachi West, followed by from Krachi East (189; 5.1\%) and Central Tongu (197; 5.3\%) (Table 1).

\section{TB notification and trends}

During the period 2013-2017, an overall downward trend of $8.6 \%$ was observed in the notification of incident TB cases from 70 to 64 cases per 100,000 population $(p=0.11)$. The case notification rate of new pulmonary bacteriologically confirmed cases, on the other hand, rose by $25 \%$ from 24 to 30 cases per 100,000 population $(p=0.49)$ (Fig. 1). Five-year case notification 
Table 1 General characteristics of Patients with TB in 10 districts of Volta region, Ghana (2013-2017)

\begin{tabular}{|c|c|c|c|}
\hline Characteristics & $\begin{array}{l}\text { Male } \\
(N=2335) \\
n(\%)\end{array}$ & $\begin{array}{l}\text { Female } \\
(N=1400) \\
n(\%)\end{array}$ & $\begin{array}{l}\text { Total }(N=3735) \\
n(\%)\end{array}$ \\
\hline \multicolumn{4}{|l|}{ Age group (yeas) } \\
\hline$<15$ & $80(49.7)$ & $81(50.3)$ & $161(4.3)$ \\
\hline $15-24$ & $152(48.9)$ & $159(51.1)$ & $311(8.3)$ \\
\hline $25-34$ & $339(56.4)$ & $262(43.6)$ & $601(16.1)$ \\
\hline $35-44$ & $555(65.1)$ & $297(34.9)$ & $852(22.8)$ \\
\hline $45-54$ & $501(67.4)$ & $242(32.6)$ & $743(19.9)$ \\
\hline $55-64$ & $343(69.5)$ & $150(30.4)$ & $493(13.2)$ \\
\hline $65+$ & 365 (63.59) & $209(36.4)$ & $574(15.4)$ \\
\hline \multicolumn{4}{|l|}{ Patient category } \\
\hline New & $2225(62.2)$ & $1353(37.8)$ & $3578(95.8)$ \\
\hline Retreatment* & $98(71 \%)$ & $40(29 \%)$ & $138(3.7)$ \\
\hline Transferred in & $12(63.2)$ & $7(36.8)$ & $19(0.5)$ \\
\hline \multicolumn{4}{|l|}{ TB classification } \\
\hline Smear positive Pulmonary " & $1120(65.5)$ & $591(34.5)$ & $1711(45.8)$ \\
\hline Smear negative Pulmonary ${ }^{\S}$ & $1147(60.43)$ & 753 (39.6) & $1900(50.9)$ \\
\hline Extra pulmonary & $64(55.2)$ & $52(44.8)$ & $116(3.1)$ \\
\hline Missing -1 & $3(42.9)$ & $4(57.1)$ & $7(0.2)$ \\
\hline \multicolumn{4}{|l|}{ HIV status } \\
\hline Positive & $353(49.6)$ & $359(50.4)$ & $712(19.1)$ \\
\hline Negative & 1619 (66.6) & $813(33.4)$ & $2432(65.1)$ \\
\hline Not known & $363(61.4)$ & $228(38.6)$ & $591(15.8)$ \\
\hline \multicolumn{4}{|l|}{ District of registration } \\
\hline Central Tongu & $120(60.9)$ & 77 (39.1) & $197(5.3)$ \\
\hline Hohoe & $300(72.8)$ & $112(27.2)$ & $412(11.0)$ \\
\hline Kadjebi & $224(68.3)$ & $104(31.7)$ & $328(8.8)$ \\
\hline Keta & $280(63.6)$ & $160(36.4)$ & $440(11.8)$ \\
\hline Ketu South & $661(58.8)$ & $464(41.2)$ & $1125(30.1)$ \\
\hline Kpando & $238(64.9)$ & $129(35.1)$ & $367(9.8)$ \\
\hline Krachi East & $100(52.9)$ & $89(47.1)$ & $189(5.1)$ \\
\hline Krachi West & $78(63.4)$ & $45(36.4)$ & $123(3.3)$ \\
\hline Nkwanta South & $208(60.7)$ & $136(39.3)$ & $344(9.2)$ \\
\hline South Tongu & $126(60.0)$ & $84(40.0)$ & $210(5.6)$ \\
\hline All districts & $2335(62.5)$ & $1400(37.5)$ & $3735(100)$ \\
\hline
\end{tabular}

*include returned after default (33), relapse (55), failure (25), Multi-drug resistant (1) and other previously treated cases whose previous treatment outcome was unknown (24); "Also referred to as Pulmonary bacteriologically confirmed; ${ }^{\S}$ Clinically diagnosed

rate (CNR) of all forms of TB for the 10 districts was 65 per 100,000 and that of pulmonary bacteriologically confirmed TB was 30 per 100,000 population. The reported rate varied widely among districts, from 124 (Ketu South) to 32 (Krachi East) per 100,000 population. The 5 -year CNR of all forms of TB was less than 50 per 100 , 000 in four districts, between 51 and 100 per 100,000 in another four districts, and higher than 100 per 100,000 in two districts (Fig. 2).
Variations in the trends of CNR was observed among districts. Whilst a downward trend in CNR was noticed in Kadjebi, Central Tongu, Hohoe, Kpando, and South Tongu districts, an irregular trend was observed in Krachi East, Krachi West, Ketu South, and Nkwanta. Keta district saw a rise in CNR from 2014 through 2016 and declined thereafter. A similar trend was observed among all new and relapse $\mathrm{TB}$ cases and pulmonary bacteriologically confirmed 


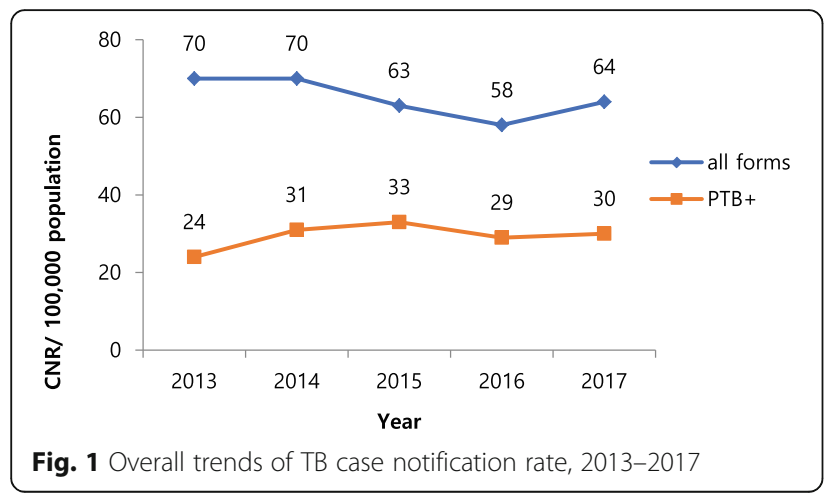

cases (Fig. 3). The biggest decline of CNR of new and relapse TB cases was observed in Kpando (130 to 47 per 100,000$)$ with a decline rate of $64 \%$, followed by Kadjebi (146 to 69) representing 53\% reduction, while Krachi West recorded the biggest rise from 18 to 54 per 100,000 , representing $200 \%$ change, followed by Krachi East (18 to 49 ) per 100,000 population, with a change of $172 \%$.

\section{TB treatment outcomes and trends}

Of the 3737 patients treated during the period, treatment outcomes of 3601(94.6\%) were evaluated as shown in Fig. 4. Of these, the overall treatment success rate (cured+completed treatment) was $82.5 \%$ (95\% CI: 81.383.8). Of all cohort of TB cases who started treatment, $486(13.5 \%)$ were reported to have died, $3.2 \%$ were lost to follow up, and $0.8 \%$ had treatment failure. Figure. 5 presents the trends of TB treatment outcomes of 2012 to 2016 cohorts. Treatment success rate decreased slightly from $83.1 \%$ (95\% CI: 80.1-85.7) in 2013 to $80.2 \%$ (95\% CI: 77.2-83.0) by December, $2017(p=0.49)$. On the other hand, mortality rate rose steadily from $9.8 \%$ in 2013 to $15.5 \%$ in $2017 ; p=0.25$, while treatment failure

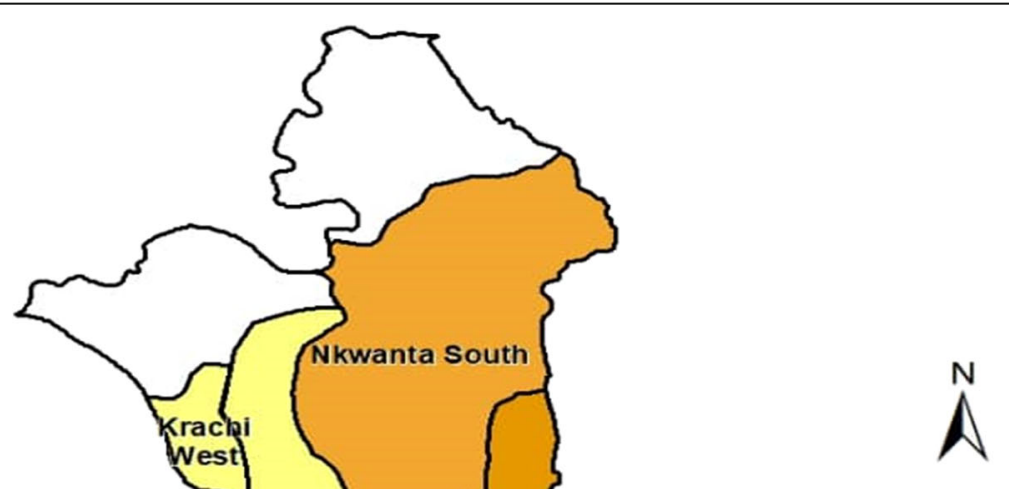

Legend

Case notification rate per 100,000

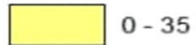

$\square 36-50$

$\square 1-60$

$61-100$

$101-125$

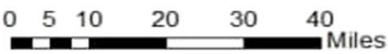

Fig. 2 TB Cases Notification Rate (all forms) by District, 2013-2017 


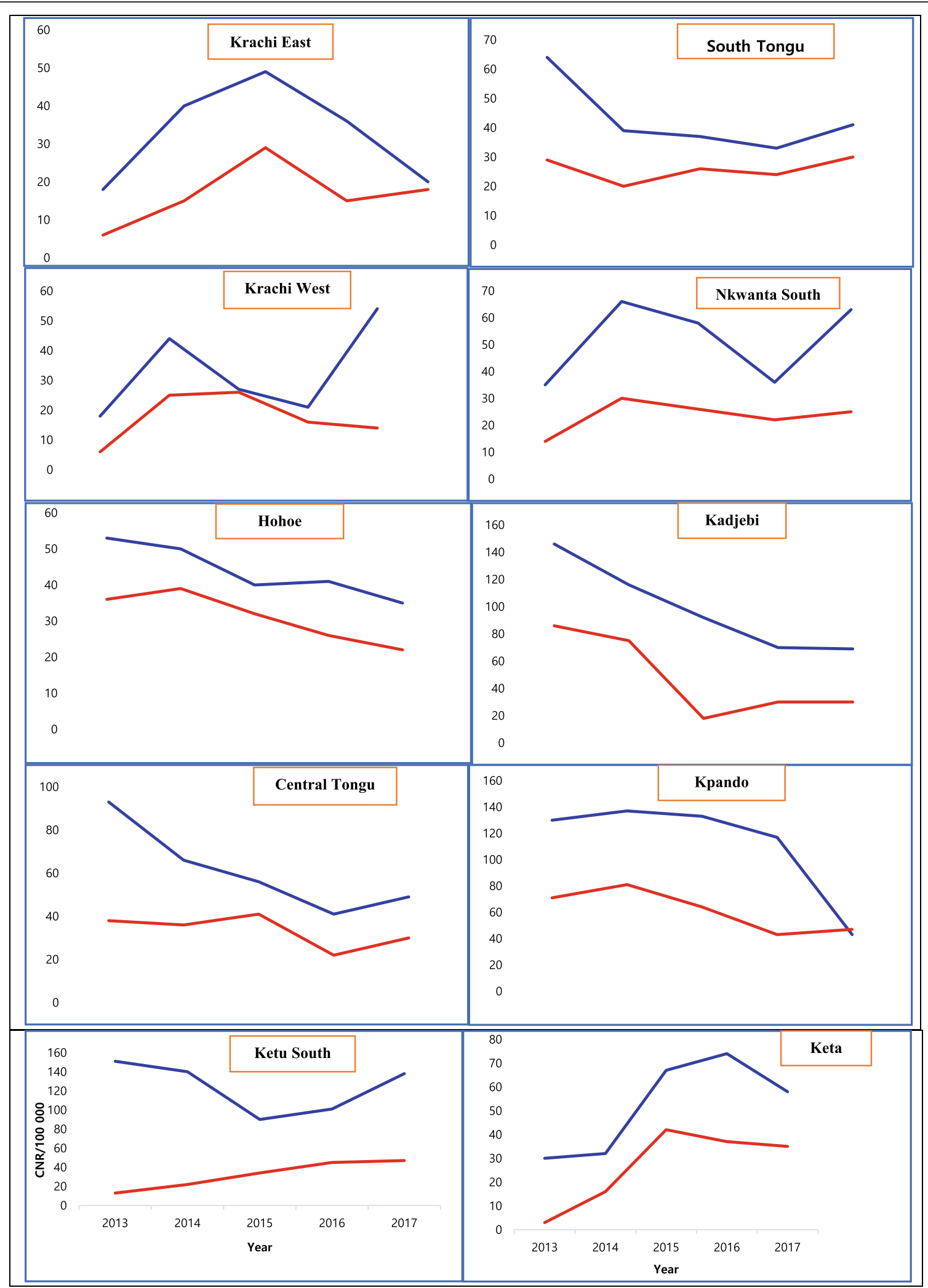

Fig. 3 District Trends in TB case Notification Rate, Volta Region, Ghana, 2013-2017. The blue line shows all forms of TB and the red line shows Smear positive pulmonary TB only 


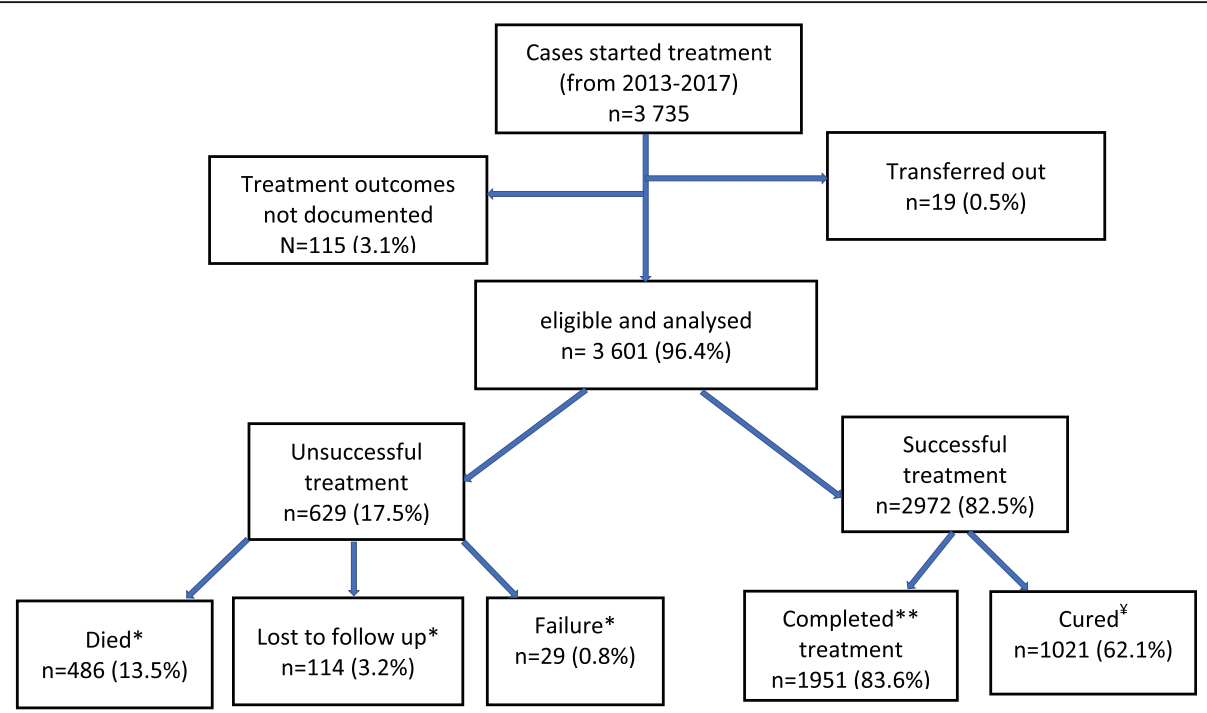

Fig. 4 Flow chart of TB treatment outcomes in 10 districts of the Volta Region, Ghana from 2012-2016

rate and lost to follow-ups decreased from 1.6 to $0.9 \%$ $(p=0.67)$ and 5.3 to $3.4 \%(p=0.72)$ respectively.

\section{Treatment outcomes by district}

Treatment success rate varied among districts with the highest rate observed in Krachi West (90.8\%; 95\% CI: 84.1-95.3) followed by Kadjebi (86.1\%; 95\% CI: 81.989.7) and Krachi East (85.9\%; 95\% CI: 79.6-90.6). South Tongu recorded the lowest treatment success rate of 70.5\% (95\% CI: 63.8-76.6) followed by Central Tongu (71.3\%; 95\% CI: 64.4-77.5). Treatment failure and death rates were highest in South Tongu (3.9 and 20.7\%) and Central Tongu (3.1 and 21.5\%) respectively. Keta, Nkwanta South, and Kpando did not record any treatment failure case. Death rate was lowest in Krachi East (3.1\%) followed by Krachi West (5.0\%). Lost to follow rate ranged from $0 \%$ in Keta to $8.5 \%$ in Krachi East during the 5 years (Table 2).

\section{Predictors of unsuccessful treatment outcomes}

As presented in Table 3, patients who returned to continue treatment after default were more likely to have unsuccessful treatment outcomes (Adjusted OR: 3.62; 95\% CI: 1.66-7.91: $P<0.001)$ compared to new cases. The odds of having unsuccessful treatment outcomes was higher among relapse cases (AOR: 1.79; 95\% CI: 0.94-3.51; $P=0.10$ ) treatment failures (AOR: 1.95; 95\% CI: $0.72-5.58 ; P=0.19)$ and cases classified as others (AOR: $1.37 ; 95 \% \mathrm{CI}: 0.48-4.18 ; P=0.58$ ) compared to new cases, however statistical evidence to support this was weak. TB and HIV co-infected patients were 94\% more likely to have unsuccessful treatment outcome (95\% CI: $1.57-2.40 ; P<0.001)$ compared to TB only patients. Except for South Tongu district, patients treated in all other 8 districts were significantly less likely to have unsuccessful treatment compared to patients treated in Central Tongu District. The proportion of

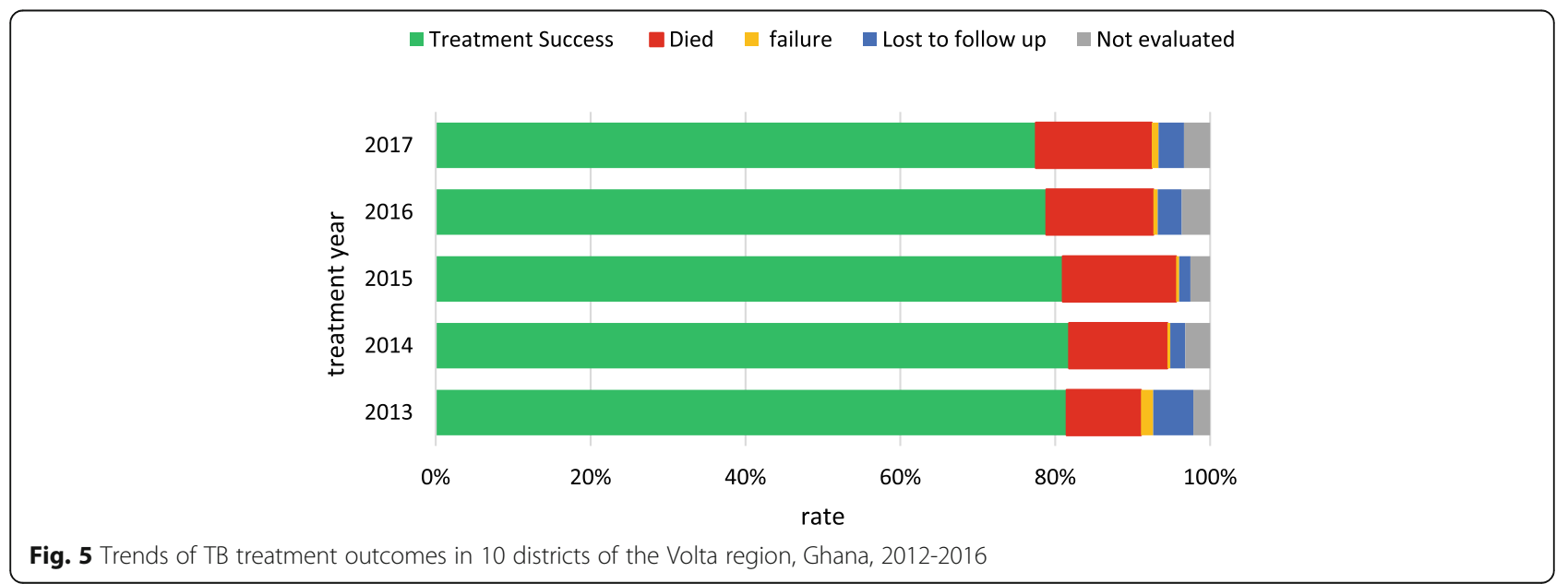


Table 2 Five-year treatment outcomes of Tuberculosis by district, 2012-2016

\begin{tabular}{|c|c|c|c|c|c|c|}
\hline \multirow[t]{3}{*}{ Districts } & \multirow{3}{*}{$\begin{array}{l}\text { Treatment Success } \\
\text { Cured + completed } \\
n(\%)(95 \% \text { Cl) }\end{array}$} & \multicolumn{3}{|l|}{ Unsuccessful } & \multicolumn{2}{|l|}{ Unknown* } \\
\hline & & Treatment failure & Died & Lost to follow up & Not documented & Transferred out \\
\hline & & $n(\%)(95 \% \mathrm{Cl})$ & $n(\%)(95 \% \mathrm{Cl})$ & $n(\%)(95 \% \mathrm{Cl})$ & $\%$ & $\%$ \\
\hline Ketu South & 885 (81.9) (79.5-84.2) & $1(0.1)(0.02-0.5)$ & $140(12.9)(11.0-15.1)$ & $54(5.1)(3.7-6.4)$ & 4.0 & 0 \\
\hline Keta & 374 (85.0) (81.3-88.2) & 0 & $66(15.0)(11.8-18.7)$ & 0 & 0 & 0 \\
\hline South Tongu & $146(70.6)(63.8-76.6)$ & 8 (3.9) (1.7-7.4) & $43(20.7)(15.5-26.9)$ & $10(4.8)(2.3-8.7)$ & 0 & 0.1 \\
\hline Nkwanta South & $284(84.8)(80.5-88.4)$ & 0 & $48(14.2)(10.8-18.5)$ & $3(1.0)(0.2-2.5)$ & 2.3 & 0.6 \\
\hline Hohoe & 306 (82.1) (77.8-85.8) & $8(2.1)(0.9-4.2)$ & 57 (15.3) (11.8-19.3) & $2(0.5)(0.07-1.9)$ & 9.2 & 0.2 \\
\hline Kpando & $311(85.2)(81.1-88.7)$ & 0 & 48 (13.2) (9.9-17.1) & 6 (1.6) (0.6-3.5) & 0 & 1.0 \\
\hline Kadjebi & 279 (86.1) (81.9-89.7) & $1(0.3)(0.07-1.7)$ & $31(9.6)(6.7-13.3)$ & $13(4.0)(2.2-6.8)$ & 0 & 1.2 \\
\hline Krachi West & 108 (90.7) (84.1-95.3) & $1(1.0)(0.02-4.6)$ & $6(5.0)(1.8-10.7)$ & 4 (3.3) (1.0-8.3) & 0 & 3.3 \\
\hline Central Tongu & 139 (71.3) (64.4-77.5) & $6(3.1)(1.1-6.6)$ & $42(21.5)(15.9-27.9)$ & $8(4.1)(1.8-7.8)$ & 0 & 1.0 \\
\hline Krachi East & $140(85.9)(79.6-90.8)$ & $4(2.5)(0.7-6.2)$ & $5(3.1)(1.0-7.0)$ & $14(8.5)(4.8-13.9)$ & 12.7 & 1.1 \\
\hline All districts & 2972 (82.5) (81.3-83.8) & $29(0.8)(0.5-1.2)$ & 486 (13.5) (12.4-14.7) & $114(3.2)(2.6-3.8)$ & 3.1 & 0.5 \\
\hline
\end{tabular}

*Not included in estimating treatment outcomes of patients

patients with unsuccessful treatment in South Tongu (29.5\%) was not statically different from that from Central Tongu (28.7\%). Year of treatment, age, sex and patient classification did not predict treatment outcomes.

\section{Discussion}

\section{Case notification rate and trends}

The WHO has noted that the disease burden attributed to TB is falling in most countries, but not fast enough to reach the first milestones of the End TB Strategy. The TB incidence rate per 100,000 population, therefore, needs to be falling at about $5 \%$ per year to achieve the set target by 2020 [2]. This study has demonstrated an insignificant decline in the notification rate of all forms of $\mathrm{TB}$, with an average decline rate of $8.8 \%$ per year. The rate of decline is however far higher than the $1.5 \%$ global rate in the TB incidence per year during 2000-2017 and $4 \%$ in the WHO African Regions during the same period [2]. This could imply that the Volta region is on course to achieving the milestone for a reduction in TB cases by $10 \%$ per year by 2025 , as set in the End TB strategy [10]. According to the Ghana health services, TB case notification in the country has declined in the last 5 years in all regions except Western and Brong Ahafo Regions [11]. However, the decline could either be due to a true reduction of the disease burden in the population or as a result of low case detection due to inadequate diagnostic facilities, weak surveillance systems, inadequate knowledge about the disease, and stigma at the community level [12], which needs further investigation. Other African countries have reported varied trends in TB case notification over the years. For instance, while Damemew et al. [13] and Senedu et al. [14] observed a downward trend in CNR of all forms of TB from the years 2011-2015 in Ethiopia, Shallo and colleague [15] noticed a consistent rise in case notification of TB during 2007-2011 in 25 districts of Arsi zone of Central Ethiopia. In Papua New Guinea, Aia et al. [16] discovered an increasing trend of TB case notification during 2008-2016 and a stabilized trend during 2015-2016. These variations in the trends of TB CNR could be as a result of differences in the period of study or differences in geographical location.

The overall CNR of all forms of TB was estimated to be 65 cases per 100,000 population, slightly higher than the Volta Regional average of 60 cases per 100,000 population in 2016 [17]. The estimated rate is however twice lower than the 2017 estimate of 133 cases per 100, 000 Ghanaian population [2]. Wide variation of TB case notification rate observed among the districts studied and that of the country's average could be a function of clinical diagnostic abilities, health care access and quality of the district surveillance system to capture cases rather than a true difference in the burden of TB by place. This, however, remains to be explored whether the variability in CNR at the district level reflects the true differences in disease burden, differences in case detection and reporting, or both.

\section{TB treatment outcomes}

Diagnosis and successful treatment of people with TB avert millions of deaths each year that are due to the disease. However, TB treatment programs in most developing countries have not been effective as expected and hence there exist huge and persistent gaps in detection and treatment [2]. Assessment of TB treatment outcomes and the predictors for poor treatment outcomes is one of the major indicators for the evaluation of the performance of any TB control program. Contrary to previous studies in Ghana [5], and Ethiopia [18], our 
Table 3 Logistic regression of patient and disease characteristics as predictors of unsuccessful treatment outcomes

\begin{tabular}{|c|c|c|c|c|c|c|c|}
\hline Variable & $\begin{array}{l}\text { Unsuccessful treatment } \\
n(\%)\end{array}$ & COR & $95 \% \mathrm{Cl}$ & $P$-value & AOR & $95 \% \mathrm{Cl}$ & $P$-value \\
\hline Age group (years) & & & & 0.37 & & & \\
\hline$<15$ & $22(14.4)$ & 1 & & & & & \\
\hline $15-64$ & $516(17.9)$ & 1.29 & $0.82-2.1$ & & & & \\
\hline $64+$ & $91(16.3)$ & 1.16 & $0.69-1.91$ & & & & \\
\hline Sex & & & & 0.33 & & & \\
\hline Female & $225(16.7)$ & 1 & & & & & \\
\hline Male & $404(17.9)$ & 1.09 & $0.91-1.31$ & & & & \\
\hline Patient category & & & & 0.002 & & & \\
\hline New & $593(17.1)$ & 1 & & & 1 & & \\
\hline Default & $14(48.3)$ & 4.52 & $2.16-9.41$ & & 3.62 & $1.66-7.91$ & 0.001 \\
\hline Relapse & $13(25.5)$ & 1.56 & $0.88-3.12$ & & 1.73 & $0.89-3.36$ & 0.10 \\
\hline Treatment Failure & $5(22.7)$ & 1.42 & $0.52-3.87$ & & 1.99 & $0.72-5.58$ & 0.18 \\
\hline Others* & $4(20.0)$ & 1.21 & $0.40-3.63$ & & 1.37 & $0.45-4.18$ & 0.58 \\
\hline TB classification ${ }^{\S}$ & & & & 0.010 & & & \\
\hline EP & $14(13.1)$ & 1 & & & 1 & & \\
\hline PP & $255(15.4)$ & 1.21 & $0.68-2.16$ & & 0.96 & $0.54-1.74$ & 0.90 \\
\hline PN & $360(19.5)$ & 1.61 & $0.91-2.85$ & & 1.29 & $0.72-2.31$ & 0.40 \\
\hline HIV status & & & & $<0.001$ & & & \\
\hline Negative & $347(14.7)$ & 1 & & & 1 & & \\
\hline Positive & $180(26.5)$ & 2.09 & $1.71-2.57$ & & 1.94 & $1.57-2.40$ & $<0.001$ \\
\hline Unknown & $102(18.2)$ & 1.29 & $1.01-1.64$ & & 1.17 & $0.91-1.52$ & 0.22 \\
\hline District of treatment & & & & $<0.001$ & & & \\
\hline Central Tongu & $56(28.7)$ & 1 & & & 1 & & \\
\hline Keta & $66(15.0)$ & 0.44 & $0.29-0.66$ & & 0.49 & $0.28-0.67$ & 0.001 \\
\hline Hohoe & $67(17.9)$ & 0.54 & $0.36-0.82$ & & 0.61 & $0.39-0.93$ & 0.02 \\
\hline Ketu South & $195(18.6)$ & 0.55 & $0.39-0.77$ & & 0.51 & $0.36-0.74$ & $<0.001$ \\
\hline Krachi West & $11(9.2)$ & 0.25 & $0.13-0.51$ & & 0.29 & $0.15-0.59$ & 0.001 \\
\hline Krachi East & $23(14.1)$ & 0.41 & $0.24-0.69$ & & 0.45 & $0.26-0.78$ & 0.005 \\
\hline Kpando & $54(14.8)$ & 0.43 & $0.28-0.66$ & & 0.44 & $0.28-0.69$ & $<0.001$ \\
\hline Nkwanta South & $51(15.2)$ & 0.45 & $0.29-0.68$ & & 0.48 & $0.31-0.75$ & 0.001 \\
\hline South Tongu & $61(29.5)$ & 1.03 & $0.67-1.59$ & & 1.11 & $0.71-1.72$ & 0.65 \\
\hline Kadjebi & 45 (13.9) & 0.40 & $0.26-0.62$ & & 0.41 & $0.26-0.64$ & $<0.001$ \\
\hline Year of registration & & & & 0.29 & & & \\
\hline 2013 & $126(16.9)$ & 1 & & & & & \\
\hline 2014 & $119(15.6)$ & 0.91 & $0.69-1.91$ & & & & \\
\hline 2015 & $119(17.0)$ & 1.00 & $0.76-1.32$ & & & & \\
\hline 2016 & $119(18.1)$ & 1.08 & $0.82-1.43$ & & & & \\
\hline 2017 & $146(19.8)$ & 1.21 & $0.93-1.57$ & & & & \\
\hline
\end{tabular}

${ }^{\varsigma}$ missing value: 2; COR Crude odds ratio; $A O R$ Adjusted odds ratio, EP Extrapulmonary, PP Pulmonary positive, PN Pulmonary negative

results point to a declined performance of treatment outcomes in 10 districts of the Volta Region during 20122016 treatment period. Generally, while treatment success and cure rates declined, the proportion of people who died due to $\mathrm{TB}$, experienced treatment failure, and those lost to follow up showed fluctuating trends over the years but with slight increases from 2015 to 2016. This poor performance could be due to patients' delay in seeking TB care as a result of stigma, lack of knowledge regarding TB signs and symptoms, inadequate community 
involvement in TB care, and lack of treatment supervision $[19,20]$. Community TB care, an intervention that recognises social capital and connectedness as a tool to effective TB care and prevention has been reported to be effective in improving TB treatment outcomes in many parts of the world, including Ghana [5, 21, 22], hence needs to be pursued vigorously in the Volta region in order to achieve improved treatment outcomes. The study further revealed that about 8 in 10 of a cohort of patients with TB treated during the period had a successful treatment outcome. This result is lower than Ghana's average (85\%) [2], and rates reported in previous studies in Ghana (87.7\%) [5], Iran (83.1\%) [23], and a pooled analysis in Ethiopia [24]. Our finding is however consistent with other previous studies in Kenya (82.4\%) [25], and South Africa (82.2\%) [26], and the global average of $82 \%$ in 2017 estimated by the WHO [2]. Variations in treatment outcomes were noticed among districts, with South Tongu and Central Tongu having the poorest treatment success rates of 70.5 and $71.3 \%$ respectively as a result of high case fatality rates (20.7\%) and (21.5\%). Keta, Kpando, Kadjebi, Nkwanta South, Krachi East, and Krachi West had treatment success rates above the study's average. The reason for the variations in treatment success rate could be due to differences in programme management and TB/HIV co-infection since comorbidity has been reported to have a negative influence on $\mathrm{TB}$ treatment [27]. TB Treatment success rate of $\geq 90 \%$ is required by control programmes in order to achieve the End TB Strategy targets by 2025 [11]. Coordinated efforts among tuberculosis control programs and health care professionals in assessing patient barriers to adherence and the use of innovations and 'enablers' that can assist the patient in adhering to the recommended therapy are fundamental requirements for achieving the milestones and targets of the End TB Strategy [2, 28]. Essentially, poor treatment adherence, which can lead to treatment failure, relapse, and the emergence of drug-resistant strains is one of the obstacles in controlling the TB epidemic [29, 30]. In this study, lost to follow up as an unsuccessful treatment outcome is comparatively lower than the findings of Kefale and Anagaw [31] and Gebrezgabiher and colleagues [32], in southwest Ethiopia who reported lost to follow up rate of 10.6 and $11.1 \%$ respectively. TB treatment interruption is an important public health problem. Patients who interrupt treatment may continue to transmit the infection to healthy people or acquire drug-resistance TB strains and consequently treatment failure [33].

TB mortality is a key indicator for monitoring progress towards the 2020 and 2025 milestones. In this study, the proportion of patients with TB who died due to the disease (13.5\%) though lower than the global average (16\%), a case fatality rate (CFR) of less than $6 \%$ is required to achieve the 2025 global milestone for reductions in TB deaths [2]. Our estimated CFR is consistent with a similar study in Accra, Ghana (12.6\%) [34], but higher than what was found in Southern Ethiopia (3.4\%) [32]. The high mortality rate due to TB could be attributed to patients' delay in seeking treatment after symptoms have developed, as a result of poor patients' knowledge and awareness of TB symptoms and the need for prompt consultation with healthcare services for diagnosis and treatment [19]. Contrary to the global trend [2], CFR in this study increased by about $58 \%$ over the period, a worrying phenomenon that calls for a coordinated effort by all stakeholders to reverse. We found a varied degree of CFR among districts, with the highest rates recorded in Central Tongu (21.5\%) and South Tongu (20.7\%) districts and lowers in Krachi East (3.1\%) and Krachi West (5.1\%). Other previous studies have reported a varying degree of TB death across geographical location. For instance Malede et, al [35]. in their study in Northeast Ethiopia reported 8.1\% death rate, Ukwaja, Alobu, Ifebunandu, and Osakwe [36] in Southeastern Nigeria reported 5\% deaths between 1999 and 2008, Gebrezgabiher, et al. [32] in Southern Ethiopia reported 3.4\% between 2008 and 2013. This variation could be attributed to differences in TB care in different areas and improvement of care over the years.

Treatment failure as an unsuccessful treatment outcome is a major threat to the control of TB as these patients are at higher risk of developing drug-resistant resistant $\mathrm{TB}$ and often associated with poor retreatment outcomes [37]. The treatment failure rate among bacteriologically confirmed TB cases in this study though low, need to further reduce since these patients are likely to develop multi-drug resistant strains if not managed well.

\section{Predictors of unsuccessful treatment outcomes}

Ascertaining the factors that predict unsuccessful treatment outcomes is essential to evaluating the performance of TB control programs and to design effective interventions [38]. Studies conducted across different populations identified various factors that could affect treatment outcomes of patients with $\mathrm{TB}$ $[39,40]$. Consistent with previous studies $[25,27,40-$ 42] in South Africa [43] and Ghana [26], we found in this study that the occurrence of unsuccessful treatment outcomes was 1.94-fold higher among TB and HIV co-infected patients compared to patients with only TB. The unsuccessful treatment outcomes among TB/HIV co-infected patients in this study could be due to drug interactions between rifamycins (rifampin or rifabutin) and some antiretroviral agents [44] as well as malabsorption of anti-TB drugs among patients with advanced HIV [45], leading to low serum 
concentrations of drugs and hence unsuccessful treatment outcomes [46]. A similar study reported that TB/HIV co-infections without the use of AntiRetroviral Therapy (ART) was associated with poor treatment outcome [47].

Unsuccessful prior TB treatment has a significant impact on subsequent treatment outcomes, with patients who returned to treatment after a prior interruption, who failed prior treatment, and those who relapsed doing poorly. In this study, patients who defaulted prior treatment had 3.62 higher odds of failing subsequent treatment compared to new patients. Poor treatment outcomes among these patients could mainly be due to mycobacterial resistance as a result of having been exposed to incomplete treatment [33, 48]. Due to serious consequences of TB treatment interruption, pragmatic efforts that ensure treatment compliance and completion are required to minimize the chances of having unsuccessful treatment outcomes and subsequent development of drug resistance. Understanding the factors that prevent patients from adhering to treatment can help minimize default.

Unlike previous studies which found old age as a risk factor for unsuccessful treatment outcome [35], factors, such as sex, age, and type of patients in this current study were not predictors of unsuccessful treatment outcomes.

This study is the first research in Ghana comparing TB programme performance of several BMCs. This provides a broad perspective of TB performance in a particular region, which may facilitate the identification of non-performing districts for better allocation of resources. Additionally, analysis of trends of TB CNR is rare in Ghana. Trend analysis of TB CNR helps to monitor the progress of achieving the programme's targets of reducing TB incidence by 2030 .

Although we believe our report presents significant lessons relevant for programme planning and implementation, it is important to acknowledge the following limitations. Firstly, the information used for the analysis was derived from routine data with potential for errors in recording, and between observer variability that is inherent in the collection and entry. This could lead to the observation of spurious results. However, the routine application of thorough checks in the registers by district and regional TB coordinators reduce the probability of these errors. Double data entry was independently done and compared by two of the co-authors with differences validated and corrected with the primary source to reduce errors. Secondly, treatment outcomes of nearly $4 \%$ of patient were not known and hence were excluded from the estimation of treatment outcomes. This could have biased our estimates of treatment outcomes and risk, resulting in under or overestimation.

\section{Conclusion}

This analysis demonstrates an unimproved TB case notification and treatment success rates in 10 districts of Volta Region, Ghana during 2013-2017, with wide inequalities among districts. The study indicates that nearly 2 in $10 \mathrm{~TB}$ patients are unsuccessfully treatment, which is strongly influenced by returned after treatment interruption and co-morbidity with HIV infection. Sustained and proven interventions such as community $\mathrm{TB}$ DOTS, provision of "enablers" to patients, and health system efficiency may impact positively on case notification and treatment outcomes to achieve the elimination goal. Contact tracing of bacteriologically positive TB patients and targeted screening among high-risk groups can improve case notification. Additionally, strengthened TB/HIV collaborative activities such as testing TB patients for HIV and treating co-infected patients with anti-retroviral is required in order to improve TB treatment outcomes among co-infected patients.

\section{Abbreviations \\ AIDS: Acquired Immunodeficiency Syndrome; BMU: Basic Management Unit; CNR: case Notification Rate; DOTS: Directly Observed Treatment Short-course; HIV: Human Immunodeficiency Virus; NTBCP: National Tuberculosis Control Programme; PLHIV: People Living with HIV; TB: Tuberculosis; WHO: World Health Organization}

\section{Acknowledgements}

Authors are grateful to health authorities and staff, particularly the TB coordinators of all participating districts for their support and permission to carry out and publish this study.

\section{Author's contributions}

EO led the study design and drafting of the paper. JD contributed to the design and critically reviewed the first draft. SO, DA, BAD, AO, and AGK reviewed the literature and collected data, SO and EO analysed and interpreted data. All authors read and approved the final manuscript.

Funding

There was no funding support for this study.

\section{Availability of data and materials}

The datasets used during the current study are available from the corresponding author on reasonable request.

\section{Ethics approval and consent to participate}

Ethical approval was obtained from the University of Health and Allied Sciences' ethical review committee. District directors of health services of the participating districts consented before data were extracted. There was no direct contact with patients, hence consent to participate was not applicable.

\section{Consent for publication}

Not applicable.

\section{Competing interests}

The authors declare that they have no competing interest.

\section{Author details}

${ }^{1}$ Department of Population and Behavioural Sciences, School of Public Health, University of Health and Allied Sciences, Ho, Ghana. ${ }^{2}$ Department of Epidemiology, School of Public Health, University of Health and Allied Sciences, Ho, Ghana. 
Received: 3 August 2019 Accepted: 14 November 2019 Published online: 17 December 2019

\section{References}

1. World Health Organization. Global tuberculosis Report 2017. Geneva: WHO 2018

2. World Health Organization. Global tuberculosis report 2018. Geneva: WHO; 2019. Licence: CC BY-NC-SA 3.0 IGO

3. World Health Organization. Treatment of Tuberculosis: guidelines- $4^{\text {th }}$ ed. 2010; WHO/HTM/TB/2009.420.

4. Keshavje S, Farmer PE. Tuberculosis, drug resistance, and the history of modern medicine. N Engl J Med. 2012;367:931-6.

5. Amo-Adjei J, Awusabo-asare K. Reflections on tuberculosis diagnosis and treatment outcomes in Ghana. Arch Public Health. 2013;71(22):1-8. https:// doi.org/10.1186/2049-3258-71-2.

6. Ghana Health Service. Ghana Health Service. In: Annual Report. Accra: Ghana. unpublished; 2014.

7. Tetteh A. K, Edward A, Joseph O, Langbong B, and Irene A. An Evaluation of Treatment Outcomes in a Cohort of Clients on the DOTS Strategy, 20122016. Tuberculosis Research and Treatment volume 2018, Article ID 4287842, 7 pages https://doi.org/10.1155/2018/4287842

8. Volta Region Health Directorate. 2015 Annual report, GHS, Volta region, Ghana. Unpublished

9. World Health Organization. Definitions and reporting framework for tuberculosis, 2013 revision. 2014; WHO/HTM/TB/2013.2.

10. World Health Organization. The end TB strategy. Global strategies and targets for TB prevention, care and control after 2015. March, 2014; A67/11-14.

11. Ghana Health Services. 2018 annual report, GHS, Accra Ghana. unpublished.

12. Amenuvegbe GK, Francis A, Binka F. Low tuberculosis case detection: A community and health facility-based study of contributory factors in the Nkwanta South district of Ghana. BMC Res Notes. 2016;9:330.

13. Dememew ZG, Habte D, Melese M, Hamusse SD, Nigussie G, Hiruy N, et al. Trends in tuberculosis case notification and treatment outcomes after interventions in 10 zones of Ethiopia. Int j Tuberc lung dis. 2016; 20(9):1192-8.

14. Gebreegziabher SB, Yimer SA, Bjune GA. Tuberculosis case notification and treatment outcomes in west Gojjam zone, Northwest Ethiopia: a five-year retrospective study. J Tuberc Res. 2016:4:23-33.

15. Hamusse SD, Demissie M, Lindtjørn B. Trends in TB case notification over fifteen years: the case notification of 25 Districts of Arsi Zone of Oromia Regional State, Central Ethiopia. BMC Public Health. 2014;14:304.

16. Paul Aia, Lungten Wangchuk, Fukushi Morishita, Jacob Kisomb, Robin Yasi, Margaret Kal, et al. Epidemiology of tuberculosis in Papua New Guinea: analysis of case notification and treatment outcome data, 2008-2016 Surveillance Report WPSAR. 2018; Vol 9, No 2. doi: https://doi.org/10.5365/ wpsar.2018.9.1.006

17. Ghana Health Service. 2016 Annual Report. GHS, Ghana, Accra https://doi. org/10.1136/bjo.2010.193169.

18. Dangisso MH, Datiko DG, Lindtjørn B. Trends of tuberculosis case notification and treatment outcomes in the Sidama zone, southern Ethiopia: ten-year retrospective trend analysis in urban-rural settings. PLoS One. 2014; 9(12):e114225. https://doi.org/10.1371/journal.pone.0114225

19. Osei E, Akweongo P, Binka F. Factors associated with DELAY in diagnosis among tuberculosis patients in Hohoe municipality, Ghana. BMC Public Health. 2015;15(1):721.

20. Addy SA, Osei E, Komesuor J, Acquah E, Anku PJ, Enowbeyang TE, Ishaque $\mathrm{SF}$, and Amu H. Community contribution to Tuberculosis care in the Krach West District of Ghana: A qualitative study. Tuberculosis Research and Treatment. Volume 2019, Article ID 5039197, 8 pages https://doi.org/10 $1155 / 2019 / 5039197$

21. Zhang H, Ehiri J, Yang H, Tang S, Li Y. Impact of community-based DOT on tuberculosis treatment outcomes: a systematic review and meta-analysis. PLoS One 2016; 11(2): e0147744. doi: https://doi.org/10.1371/journal.pone. 0147744.

22. Agyemang BS, Kodama T, Sata F, Bonsu G, Osawa E. Community-involved strategy to improve tuberculosis (TB) treatment outcomes in eastern region of Ghana. J National Inst Public Health. 2012;61(4):357-65.

23. Khazaei S, Hassanzadeh J, Rezaeian S, Ghaderi E, Khazaei S, Hafshejani AM, et al. Treatment outcomes of new smear-positive pulmonary tuberculosis patients in Hamadan, Iran: a registry-based cross-sectional study. Egypt J Chest Dis Tuberc. 2016:65(4):825-30.

24. Eshetie S, Gizachew M, Alebel A, van Soolingen D. Tuberculosis treatment outcomes in Ethiopia from 2003 to 2016, and impact of HIV co-infection and prior drug exposure: a systematic review and meta-analysis. PLoS One. 2018;13(3):e0194675. doi. https://doi.org/10.1371/journal.pone.0194675.

25. Mibei D, Kiarie J, Wairia A, Kamene M, Okumu M. Treatment outcomes of drug-resistant tuberculosis patients in Kenya. Int J TubercLung Dis. 2016: 20(11):1477-82.

26. Jacobson KB, Moll AP, Friedland GH, Shenoi SV. Successful tuberculosis treatment outcomes among HIV/TB co-infected patients down referred from a district hospital to primary health clinics in rural South Africa. PloS ONE. 2015; 10(5): e0127024. https://doi.org/10.1371/journal.pone.0127024 PMID: 25993636

27. Osei E, Der J, Owusu R, Kofie P, Axame WK. The burden of HIV on Tuberculosis patients in the Volta Region of Ghana from 2012 to 2015 : implication for Tuberculosis control. BMC Infect Dis. 2017;17(504):1-9. https://doi.org/10.1186/s12879-017-2598-z.

28. Basha Ayele GN. Treatment outcome of tuberculosis in selected health facilities of Gedeo zone, southern Ethiopia: a retrospective study. Mycobact Dis. 2015:5(194):1-9.

29. Sisay S, Mengistu B, Erku W, Woldeyohannes D. Directly observed treatment short-course (DOTS) for tuberculosis control program in Gambella regional state, Ethiopia: ten years experience. BMC Res Notes. 2014;7(1):44

30. Rangaka MX, Cavalcante SC, Marais BJ, Thim S, Martinson NA, Swaminathan $\mathrm{S}$, et al. Controlling the seedbeds of tuberculosis: diagnosis and treatment of tuberculosis infection. Lancet. 2015; 386 (10010):2344-2353. https://doi. org/10.1016/S0140-6736(15)00323-2 PMID: 26515679.

31. Kefale AT, Anagaw YK. Outcome of tuberculosis treatment and its predictors among HIV infected patients in Southwest Ethiopia. Int J Gen Med. 2017; 161(169):1-9.

32. Gebrezgabiher G, Romha G, Ejeta E, Asebe G. Treatment outcome of tuberculosis patients under directly observed treatment short course and factors affecting outcome in southern Ethiopia : a five-year retrospective study. PLoS One. 2016;11(2):1-10. https://doi.org/10.1371/journal.pone.0150560.

33. World Health Organization. Multidrug-Resistant Tuberculosis (MDR-TB). WHO, 2013 update. Retrieved from www.who.int/tb on 16th July 2019.

34. Ohene S-A, Bakker MI, Ojo J, Toonstra A, Awudi D, Klatser P. Extrapulmonary tuberculosis: a retrospective study of patients in Accra Ghana. PLoS ONE. 2019;14(1):e0209650. https://doi.org/10.1371/journal.pone. 0209650.

35. Malede A, Shibabaw A, Hailemeskel E, Belay M, Asrade S. Bacteriology \& Parasitology Treatment Outcome of tuberculosis patients and associated risk factors at Dessie and Woldiya town health institutions, Northeast Ethiopia : a retrospective cross-sectional study. J Bacteriol Parasitol. 2015; 6(5):1-8. https://doi.org/10.4172/2155-9597.1000240.

36. Ukwaja KN, Oshi SN, Alobu I, Oshi DC. Profile and determinants of unsuccessful tuberculosis outcome in rural Nigeria: Implications for tuberculosis control. World J Methodol. 2016; 6(1):118-125. Published 2016 Mar 26. doi:https://doi.org/10.5662/wjm. v6.i1.118.

37. Dooley KE, Lahlou O, Knudsen J, Elmessaoudi MD, Cherkaoui I, El Aouad R. Risk factors for tuberculosis treatment failure, default, or relapse and outcomes of retreatment in Morocco. BMC Public Health. 2011;11(1):140. https://doi.org/10.1186/1471-2458-11-140.

38. Melese A, Zeleke B. Factors associated with poor treatment outcome of tuberculosis in Debre Tabor, northwest Ethiopia. BMC Research Notes. 2018;11(25):1-6. https://doi.org/10.1186/s13104-018-3129-8.

39. Ali SA, Mavundla TR, Fantu R, Awoke T. Outcomes of TB Treatment in HIV Coinfected Patients with TB in Ethiopia: a cross-sectional analytic study. BMC Infectious Diseases. 2016;16(640). https://doi.org/10.1186/s12879-016-1967-3.

40. Berhe G, Enquselassie F, Aseffa A. Treatment outcome of smear-positive pulmonary tuberculosis patients in Tigray region, Northern Ethiopia. BMC Public Health. 2012;12(537):1-9.

41. Van der Werf MJ, Ködmön C, Zucs P, Hollo V, Amato-Gauci AJ, Pharris A Tuberculosis and HIV coinfection in Europe: looking at one reality from two angles. AIDS. 2016;30(18):2845-53.

42. Burman WJ, Jones BE. Treatment of HIV-related tuberculosis in the era of effective antiretroviral therapy. Am J Respir Crit Care Med. 2001;164:7-12.

43. Elliott E, Draper HR, Baitsiwe P, Claassens MM. Factors affecting treatment outcomes in drug-resistant tuberculosis cases in the northern cape, South Africa. Public Health Action. 2014;4(3):1-3. 
44. Holland DP, Hamilton CD, Weintrob AC, Engemann JJ, Fortenberry ER, Peloquin CA, Stout JE. Therapeutic drug monitoring of antimycobacterial drugs in patients with both tuberculosis and advanced human immunodeficiency virus infection. Pharmacotherapy. 2009;29:503-10.

45. Karo B, Krause G, Hollo V, van der Werf MJ, Castell S, Hamouda O, Haas W. Impact of HIV infection on treatment outcome of tuberculosis in Europe. AIDS. 2016;30(7):1089-98.

46. Sterling TR, Pham PA, Chaisson RE. HIV infection-related tuberculosis: clinical manifestations and treatment. Clin Infect Dis. 2010;50:S223-30.

47. Vijay S, Kumar P, Chauhan LS, Rao SV, Vaidyanathan P. Treatment outcome and mortality at one and half year follow-up of HIV infected Patients with TB under TB control programme in a district of South India. PLOS ONE. 2011;6(7):e21008.

48. do Prado TN, Rajan JV, Miranda AE, dos Santos Dias E, Cosme LB, Gonc L, Possuelo A. Clinical and epidemiological characteristics associated with unfavourable tuberculosis treatment outcomes in TB-HIV co-infected patients in Brazil: a hierarchical polytomous analysis. braz j infect dis. 2017; 21(2):162-70.

Ready to submit your research? Choose BMC and benefit from:

- fast, convenient online submission

- thorough peer review by experienced researchers in your field

- rapid publication on acceptance

- support for research data, including large and complex data types

- gold Open Access which fosters wider collaboration and increased citations

- maximum visibility for your research: over $100 \mathrm{M}$ website views per year

At $\mathrm{BMC}$, research is always in progress.

Learn more biomedcentral.com/submissions 